\title{
Etiologia da mastite subclínica em bovinos leiteiros do agreste meridional do Estado de Pernambuco
}

\section{Etiological mastitis subclinical in dairy cattle on meridional agreste of Pernambuco State - Brazil}

\author{
Marcos Eielson Pinheiro de Sá, ${ }^{*}$ Rinaldo Aparecido Mota, ${ }^{\star \star}$ Maria Isabel de Souza, ${ }^{\star \star *}$ \\ Andréa Alice da Fonseca Oliveira****
}

\begin{abstract}
Resumo
Com o objetivo de estudar a etiologia da mastite subclínica bovina no município de Garanhuns - PE, foram submetidas à análise bacteriológica 408 amostras de leite obtidas de vacas positivas $(2+$ e $3+)$ ao "California Mastitis Test" - CMT. Obteve-se $58,41 \%$ das amostras positivas ao exame bacteriológico. Dos microrganismos isolados, o mais prevalente foi o Sthapylococcus spp. $(32,48 \%)$, sendo o Staphylococcus aureus $(66,43 \%)$ a espécie mais predominante nas amostras analisadas.
\end{abstract}

Palavras-chave: bactérias; mastite; bovinos.

\begin{abstract}
Studying the etiology of bovine subclinical mastitis in agreste meridional of Pernambuco State. 408 milk samples with positive reaction for "California Mastitis Test" to 2+ and 3+ were submitted to bacteriologic analysis. Staphylococcus spp. (32,48\%) was the bacteria most prevalent and the Staphylococcus aureus the specie most predominant in the samples analised.
\end{abstract}

Keywords: bacteria; mastits; bovine.

\section{Introdução}

A mastite bovina constitui-se no maior problema sanitário relacionado à pecuária leiteira, causando grandes prejuízos econômicos decorrentes de alterações na quantidade e qualidade do leite produzido, gastos com medicamentos, assistência veterinária, descarte de animais e do leite contaminado, além de gastos com reposição do plantel (Costa, 1991). As perdas nos laticínios são devidas à queda na qualidade do produto final e diminuição no rendimento industrial para a fabricação dos derivados do leite (Langoni et al., 1991).

A forma subclínica é importante devido a uma maior prevalência nos rebanhos, ocorrendo 15 a 40 vezes mais que a forma clínica, é de difícil detecção e longa duração, tornando os animais reservatórios de microrganismos para o rebanho. A produção por quarto mamário pode estar reduzida de 10 a $46 \%$. Nos EUA, a prevalência da mastite subclínica é de $33 \%$ das vacas e o nível de infecção dos quartos mamários é de $12 \%$ (Philpot \& Nickerson, 1991).

Langoni e Domingues (1998) encontraram 40,6\% dos quartos examinados, com reação positiva $3+$ ao CMT.
McDonald (1979) relatou que os custos da enfermidade são estimados entre US\$90 e US\$250 por vaca/ano, com perdas na produção de leite em torno de US\$770 Kg/vaca/ano. A mastite subclínica representa $70-80 \%$, e a clínica, de $20-30 \%$ do total de prejuízos causados pelas mastites (Philpot, Nickerson, 1991).

Costa et al. (1995), em estudo realizado nos Estados de São Paulo e Minas Gerais, obtiveram uma porcentagem de $72,56 \%$ de animais que apresentaram, no mínimo, um quarto com CMT positivo e a porcentagem de quartos positivos foi de $46,54 \%$ para mastite subclínica.

A mastite subclínica é diagnosticada por exames baseados no conteúdo celular do leite, sendo o diagnóstico definitivo dado pela cultura com o isolamento do agente etiológico envolvido (Bouchot et al., 1985). Fagliari et al. (1983) encontraram correlação entre a reação $3+$ no CMT e o resultado positivo no exame bacteriológico em $85,6 \%$ das amostras analisadas.

A mastite pode ser de etiologia tóxica, traumática, alérgica, metabólica e principalmente infecciosa, sendo as causas infecciosas as principais, destacando-se as de origem bacteriana (Costa,1991).

\footnotetext{
* Médico Veterinário residente da Clínica de Bovinos de Garanhuns -UFRPE.

** Prof. Adjunto Doutor de Bacterioses dos animais domésticos - Departamento de Medicina Veterinária, UFRPE, Av. Dom Manuel de Medeiros s/n. Dois Irmãos, Recife/PE, Brasil. Autor para correspondência.

*** Médica Veterinária da Clínica de Bovinos de Garanhuns, UFRPE, Garanhuns, PE, Brasil.

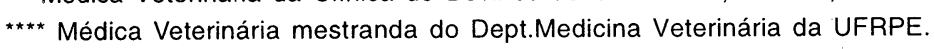


Wilson et al. (1997) encontraram $48,5 \%$ de todas as vacas examinadas com exame bacteriológico do leite positivo. Destes, mais de $85 \%$ das infecções intramamárias foram causadas por Streptococcus agalactiae, Streptococcus sp., Staphylococcus aureus e Staphylococcus coagulase negativa.

Watts (1988) citou 137 espécies de microrganismos pertencentes a 35 gêneros identificados como agentes etiológicos de mastite bovina. Os principais microrganismos causadores de mastite bovina podem ser divididos em cinco grupos: cocos Gram-positivos, bactérias Gram-negativas, corinebactérias e Actinomyces spp., Micoplasmas e outros como Nocardia spp., Prototheca spp. e leveduras (Sears et al., 1993).

O Staphylococcus aureus é o principal agente isolado da glândula mamária, com prevalências altas em todo mundo, inclusive no Brasil, onde varia de $30,5 \%$ a $83,5 \%$ (Langnegger, 1970; Harrop et al., 1975 ; Ferreiro et al., 1981 ; Silva et al., 1983 ; Nader Filho et al., 1984).

O Corynebacterium bovis, considerado patógeno menor, de importância secundária na mastite bovina, é um dos agentes de maior prevalência em mastites de acordo com levantamentos realizados em diferentes países (Costa et al., 1985) e no Brasil com prevalência variando entre $9,23 \%$ e $32,5 \%$ (Costa et al., 1985 ; Langoni et al., 1991 ; Costa et al., 1995). Entretanto, o agente é isolado de menos de $1 \%$ dos quartos nos rebanhos que adotam pré e pós "dipping" (Langoni et al., 1991 ; Costa et al., 1995).

Os Streptococcus spp. são bastante prevalentes em levantamentos realizados no Brasil, com porcentuais variando de $11,4 \%$ a $46,5 \%$ (Langnegger et al., 1970 ; Harrop et al., 1975 ; Ferreiro et al., 1981; Longo et al., 1994).

As bactérias do gênero Bacillus são saprófitas e, portanto, patógenos oportunistas. Bacillus cereus geralmente está associado a contaminações cirúrgicas e a lesões nos tetos, causando mastite aguda ou superaguda, podendo levar o animal a óbito (Blood e Radostitis, 1991).

\section{Material e métodos}

Foram estudadas 12 propriedades de criação de bovinos leiteiros, na Região do Agreste Meridional de Pernambuco, exploradas com manejo de ordenha manual.

Utilizaram-se 190 vacas leiteiras primíparas e pluríparas, puras e mestiças das raças holandês preto e branco, jersey e pardo suíço, com idades diferenciadas e em diferentes estágios de lactação. Os animais foram submetidos ao exame clínico do úbere, pela inspeção dos quartos mamários, segundo Rosemberger (1991), exame dos primeiros jatos de leite em caneca de fundo preto ou caneca telada para diagnóstico de mastite clínica e ao "California Mastitis Test" para se detectar mastite subclínica, segundo Schalm e Noorlander (1957).

Utilizaram-se 408 amostras de leite. Dos quartos mamários positivos ao CMT $(2+$ e $3+)$, coletaram-se $10 \mathrm{ml}$ de leite em frascos tipo penicilina, previamente esterilizados e identificados com o nome ou número do animal e seu teto correspondente, logo após lavagem do úbere com água e sabão, secagem com papel-toalha e prévia desinfecção do óstio do teto com álcool etílico a $70^{\circ} \mathrm{GL}$.
As amostras foram acondicionadas em caixa isotérmica, contendo gelo reciclável e encaminhadas ao laboratório de doenças infectocontagiosas do Departamento de Medicina Veterinária da UFRPE em Recife-PE.

De cada amostra foi retirada uma alíquota de $0,1 \mathrm{ml}$ de leite $e$ semeada em meios de Ágar Sangue Bovino a 10\% e Ágar Levine, incubando-se as placas em aerobiose à temperatura de $37^{\circ} \mathrm{C}$ por até 96 horas, com observações do crescimento microbiano, a cada 24 horas.

Os microrganismos isolados foram identificados, pelas características morfológicas de suas colônias, morfotintoriais através da técnica de Gram e prova da catalase. Os estafilococos obtidos foram classificados presuntivamente através de provas bioquímicas tais como: fermentação e oxidação da glicose, fermentação da maltose, Driase, fermentação do manitol, além de observação da produção de pigmentos da colônia, coagulase, presença e o tipo de hemólise em Ágar Sangue (Carter, 1988).

\section{Resultados e discussã̀o}

Os resultados dos exames bacteriológicos realizados nas 408 amostras de leite mostraram os microrganismos relacionados na Tabela 1. A Tabela 2 refere-se à classificação presuntiva das amostras de Staphylococcus spp. isoladas nas amostras de leite.

Tabela 1: Freqüências absoluta e relativa dos microrganismos isolados nas amostras de leite provenientes de vacas com mastite subclínica da Região do Agreste Meridional do Estado de Pernambuco - PE, 1999

\begin{tabular}{lcc}
\hline Microrganismo lsolado & $\begin{array}{c}\text { Frequéncia } \\
\text { Absoluta }\end{array}$ & $\begin{array}{c}\text { Freqüência } \\
\text { Relativa }\end{array}$ \\
\hline Staphylococcus spp. & 140 & $32,63 \%$ \\
Corynebacterium spp. & 57 & $13,29 \%$ \\
Streptococcus spp. & 16 & $3,73 \%$ \\
Micrococcus spp. & 03 & $0,70 \%$ \\
Bacillus spp. & 34 & $7,92 \%$ \\
Enterobacter spp. & 01 & $0,23 \%$ \\
Negativo & 178 & $41,50 \%$ \\
\hline Total & 429 & $100 \%$ \\
\hline
\end{tabular}

Tabela 2: Freqüências absoluta e relativa da classificação presuntiva das amostras de Staphylococcus sp. obtidas do leite de vacas com mastite subclínica procedente da Região do Agreste Meridional do Estado de Pernambuco - PE, 1999.

\begin{tabular}{|lcc}
\hline Espécies & $\begin{array}{c}\text { Freqüência } \\
\text { Absoluta }\end{array}$ & $\begin{array}{c}\text { Freqüência } \\
\text { Relativa }\end{array}$ \\
\hline Staphylococcus aureus & 93 & $66,43 \%$ \\
Staphylococcus intermedius & 23 & $16,43 \%$ \\
Staphylococcus hyicus & 09 & $6,43 \%$ \\
Staphylococcus epidermidis & 11 & $7,86 \%$ \\
Staphylococcus saprophyticus & 04 & $2,86 \%$ \\
\hline \multicolumn{1}{c}{ Total } & $\mathbf{1 4 0}$ & $\mathbf{1 0 0 \%}$ \\
\hline
\end{tabular}


A mastite constitui um problema para a região estudada, levando-se em consideração as perdas econômicas que podem ocorrer nos rebanhos com elevados índices de mastite subclínica (Langenegger et al., 1970 ; Costa, 1991 ; Langoni, Domingues, 1998). Os resultados obtidos neste estudo corroboram os achados de Silva et al. (1983), Nader et al. (1984), Costa (1991), Wilson et al. (1997) que relataram o Staphylococcus spp. como o agente mais prevalente em mastite subclínica bovina. Todos os rebanhos examinados não utilizavam pré e pós "dipping" e também não havia grande preocupação com a higiene do ordenhador e dos utensílios usados na ordenha. Este fato pode justificar os elevados índices de mastite subclínica, principalmente por microrganismos contagiosos.

Dentre as espécies isoladas, o Staphylococcus aureus foi 0 mais prevalente neste estudo $(66,43 \%)$, concordando com os achados de Ferreiro et al. (1981), Costa (1991), Costa et al. (1995), Martins et al. (1995) e Langoni, Domingues (1998), ressaltando-se a importância deste agente nas mastites, como causador de elevada contagem de células somáticas, redução na produção de leite e taxas de cura extremamente baixas.

Além disso, é um microrganismo capaz de invadir e replicarse no interior das células epiteliais da glândula mamária bovina, podendo este mecanismo levar a resultados falsos negativos nos exames bacteriológicos e influenciar na eficácia dos antibióticos utilizados no tratamento (Almeida et al., 1996). A presença de Staphylococcus aureus no leite além de levar ao aparecimento de mastites, indica um risco em potencial à saúde pública, principalmente quanto à formação de enterotoxinas termorresistentes, que, se ingeridas, podem levar a intoxicações alimentares. A prevalência de Staphylococcus epidermidis, incluído no grupo dos estafilococos coagulase negativa, verificada no estudo $(7,86 \%)$ encontra-se um pouco abaixo do relatado por Ferreiro et al. (1981) 16,1\%, Nader Filho et al. (1984) 11,3\% e por Langoni et al. (1991) $23,19 \%$. Normalmente são saprófitas, fazem parte da flora normal dos mamíferos e casos novos de mastite por este agente surgem predominantemente no período seco.

O isolamento de Streptococcus spp. $(3,73 \%)$ em baixos índices corrobora com os achados de Nader Filho et al. (1984) e Langoni et al. (1991). As mastites por Staphylococcus spp. e Streptococcus spp. comumente são denominadas de contagiosas e a infecção pode ocorrer de uma glândula mamária infectada para uma sadia, através das mãos do ordenhador ou equipamento de ordenha, ressaltando-se a importância de medidas de controle higiênicas e terapêuticas adequadas que, provavelmente, resultarão na redução dos índices de mastite subclínica no rebanho (Natzke, 1981).

\section{Referências bibliográficas}

ALMEIDA, R.A., MATTHEWS, E.C., GUIDRY, A.J. et al. Staphylococcus aureus invasion of bovine mamary epithelial cells. J. Dairy Sci., v. 79, n. 6, p. 1021-1026, 1996.

BLOOD, D.C., RADOSTITIS, O.M. Clínica Veterinária. 7. ed. Rio de Janeiro: Guanabara Koogan, 1991. Cap. 15, p. 424-463.

BOUCHOT, M.C., CATEL, J., CHIROL, C. et al. Diagnostic bacteriologique des infections mamaries des bovins. Recl. Med. Vet., v. 61, p. 567$577,1985$.
As 230 amostras positivas ao exame bacteriológico correspondem a $56,37 \%$ das amostras com reação $2+$ e 3+ ao CMT, corroborando com os achados de Wilson et al. (1997) que encontraram $48,5 \%$ de todas as vacas examinadas ao CMT, com positividade ao exame bacteriológico do leite. Fagliari et al. (1983) encontraram correlação entre a reação $3+$ no CMT e o resultado positivo no exame bacteriológico de $85,6 \%$.

Dentro do gênero Corynebacterium, o $C$. bovis tem sido considerado patógeno menor, de importância secundária na mastite bovina. Uma freqüência de $13,29 \%$ de isolamento deste gênero no presente estudo pode estar relacionado à ausência de medidas higiênicas no ato da ordenha, visto que são bactérias isoladas em baixos índices nos quartos mamários em rebanhos que adotam pré e pós "dipping". Blood e Radostitis (1991) ressaltam que, a baixa prevalência deste em um rebanho indica a eficiência do pré e pós "dipping" e do produto utilizado.

A adoção de pré "dipping" e antissepsia pós ordenha ("teat dipping"), utilizando produtos de concentração adequada e tempo de exposição suficiente pode reduzir a incidência da mastite subclínica na propriedade e resultar em maior produção de leite.

A presença de um agente do grupo coliforme, o Enterobacter spp., em apenas uma amostra corrobora com os achados de Costa et al. (1995), que relatam baixa prevalência de coliformes nas mastites subclínicas. No entanto, Cullor et al. (1994) enfatizam o crescimento de mastites por coliformes em geral, decorrente da ausência de medidas higiênicas no ambiente, uma vez que são agentes considerados normalmente de origem ambiental:

Para elaboração e implantação de programas de controle da mastite numa região, é importante que se conheça o estado sanitário do rebanho, condições de manejo dos animais, e que se proceda à solicitação de exames microbiológicos do leite para a confirmação do diagnóstico etiológico das mastites, principalmente quando se refere a maior ou menor prevalência de agentes contagiosos ou ambientais.

\section{Conclusões}

Os microrganismos do gênero Staphylococcus são os principais agentes de mastite subclínica na Região do Agreste Meridional de Pernambuco com freqüência de 32,63\%.

O Staphylococcus aureus foi a espécie mais isolada dentro da classificação presuntiva realizada nas cepas de Staphylococcus spp, com freqüência de $66,43 \%$.

As bactérias dos gêneros Corynebacterium e Streptococcus também merecem destaque na etiologia da mastite subclínica de bovinos na região estudada.

CARTER, G.R. Fundamentos de Bacteriologia e Virologia Veterinária. 3. ed. São Paulo: Roca, 1988, 249 p.

COSTA, O.C., CARVALHO, V.M., COUTINHO, S.D.A. etal. Corynebacterium bovis e sua importância na etiologia da mastite bovina no Estado de São Paulo. Pesq. Vet. Bras., v. 5, p. 117-120, 1985.

COSTA, E.O. da. Importância econômica da mastite bovina. Comum. Cient. Fac. Med. Vet. Zoot. USP, v. 15, p. 21-26, 1991.

, MELVILLE, P.A., RIBEIRO, A.R. et al. Índices de mastite bovina clínica e subclínica nos Estados de São Paulo e Minas Gerais. Rev. Bras. Med. Vet., v. 17, p. 215-217, 1995. 
CULLOR, J.S., TYLÊR, J., SMITH, B.P. Distúrbios da glândula mamária. In: SMITH, B.P. Tratado de Medicina Interna de Grandes Animais. São Paulo: Manole, 1994. p.1041-1060.

FAGLIARI, J..J. et al. Bovine mastitis test: comparison of CMT and bacteriological examination. Arq. Bras. Med. Vet. Zoot., v. 35, p. 309-315, 1983.

FERREIRO, L., SANTOS, E.C. dos, SILVA, N. da. Ocorrência e etiologia da mastite bovina na "zona da mata" do Estado de Minas Gerais. Arq. Esc. Vet. UFMG., Belo Horizonte, v. 33, p. 31-37, 1981.

HARROP, M.H.V., PAREIRA, L.J.G.; BRITO, J.R.F. et al. Incidência de mastite bovina na bacia leiteira da zona do agreste meridional de Pernambuco. Pesq. Vet. Bras. Ser. Vet., v. 10, p. 65-67, 1975.

LANGENEGGER, J., COELHO, N.M.C., LANGENEGGER, C.H. et al. Estudo da incidência da mastite bovina na bacia leiteira do Rio de Janeiro. Pesq. Agrop. Bras., Rio de Janeiro, v. 5, p. 437-440, 1970.

LANGONI, H., PINTO, M.P., DOMINGUES, P.F. et al. Etiologia e sensibilidade bacteriana da mastite bovina subclínica. Arq. Bras. Med. Vet. Zoot., v. 43, p. 507-515, 1991.

, DOMINGUES, P.F. Prevalência da mastite bovina e sua distribuição por quartos. Rev. Bras. Med. Vet., v. 20, p. 85-87, 1998.

LONGO, F., BEGUIN, J.C., CONSALVI, P.J. et al. Quelques données épidemiologiques sur les mammites subcliniques de la vache laitiére. Revue Méd. Vét., v. 145, p. 43-47, 1994.

MARTINS, L., CARDOSO, C.M., SANTIAGO, V. et al. Agentes causadores de mastite em bovinos no Sul do Rio Grande do Sul. CONGRESSO BRASILEIRO DE MICROBIOLOGIA, 18., 1995, Santos. Anais... Santos, 1995. p. 129.
MC DONALD, J.S. Bovine mastitis: introductory remark. J. Dairy Sci., v. 62, p. 117-160, 1979.

NADER FILHO, A., SHOCKEN-ITURRINO, R.P., ROSSI JÚNIOR, O.D. Mastite subclínica em rebanhos produtores de leite gordura $3,2 \%$. Arq. Bras. Med.Vet. Zoot., Belo Horizonte, v. 36, p. 549-558, 1984.

NATZKE, R.P. Elements of mastitis control. J. Dairy Sci., v. 64, p. 14311442, 1981.

PHILPOT, W.N., NICKERSON, S.C. Mastitis: counter attack. Louisiana Agricultural. Experiment station: Babson Bros.Co., 1991, Cap. 1, p. 3-7.

ROSENBERGER, G. Exame Clínico dos Bovinos. 3. ed. Rio de Janeiro : Guanabara Koogan, 1991. Cap. 10, p. 299-308.

SCHALM, O.W., NOORLANDER, D.O. Experiments and observation leading to development of California mastitis Test. J. Am. Vet. Assoc., v. 130, p. 199-204, 1957.

SEARS, O.W., GONZALES, R.N., WILSON, D.J. et al. Procedures for mastitis diagnosis and control. Vet. Clin. North Am.: Food Anim. Pract., v. 9, p. 445-468, 1993.

SILVA, N., FIGUEIREDO, J.B., OLIVEIRA, M. Mamite no rebanho bovino da Escola Média de Agricultura de Florestal - UFV-MG. Parte II. Freqüência e Etiologia. Arq. Bras. Med. Vet. Zoot, v. 35, p. 85-91, 1993.

WATTS, J.L. Etiological agents of bovine mastitis. Vet. Microbiol., v. 16, p. 41-46, 1988

WILSON, D.J., DAS, H.H., GONZALES, R.N. et al. Association between management practices, dairy herd characteristics, and somatic cell count of bulk tank milk. J.A.V.M.A., v. 210, p. 1499-1502, 1997. 